\title{
Modified Vogel's approximation method for transportation problem under uncertain environment
}

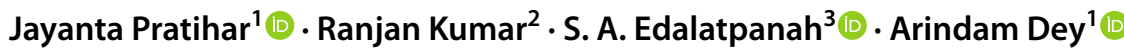

Received: 8 February 2020 / Accepted: 4 May 2020 / Published online: 29 June 2020

(c) The Author(s) 2020

\begin{abstract}
The fuzzy transportation problem is a very popular, well-known optimization problem in the area of fuzzy set and system. In most of the cases, researchers use type 1 fuzzy set as the cost of the transportation problem. Type 1 fuzzy number is unable to handle the uncertainty due to the description of human perception. Interval type 2 fuzzy set is an extended version of type 1 fuzzy set which can handle this ambiguity. In this paper, the interval type 2 fuzzy set is used in a fuzzy transportation problem to represent the transportation cost, demand, and supply. We define this transportation problem as interval type 2 fuzzy transportation problems. The utility of this type of fuzzy set as costs in transportation problem and its application in different real-world scenarios are described in this paper. Here, we have modified the classical Vogel's approximation method for solved this fuzzy transportation problem. To the best of our information, there exists no algorithm based on Vogel's approximation method in the literature for fuzzy transportation problem with interval type 2 fuzzy set as transportation cost, demand, and supply. We have used two Numerical examples to describe the efficiency of the proposed algorithm.
\end{abstract}

Keywords Fuzzy set · Interval type 2 fuzzy set · Transportation problem · Vogel's approximation method

\section{Introduction}

The fuzzy transportation problem is one of the most well-known optimization problems in the field of fuzzy set and system. This problem appears in many real-life applications, e.g., computer networks, routing, shortest path problems [1-8], communication, etc. It has been researched extensively in many engineering fields such as electronics engineering, electrical engineering, and computer science in terms of effective algorithms.

The supply and demand costs are considered as real numbers, i.e., crisp numbers in classical transportation problems. It computes a solution on the base of demand and supply. It has been applied in many fields, including optimal control, inventory, logistics management, and supply chain management. Many researchers have used fuzzy

S. A. Edalatpanah

saedalatpanah@gmail.com

1 Department of Computer Science and Engineering, Saroj Mohan Institute of Technology, West Bengal, India

2 Jain Deemed to be University, Jayanagar, Bengaluru, India

3 Department of Industrial Engineering, Ayandegan Institute of Higher Education, Tonekabon, Iran variables/numbers (especially triangular fuzzy number and trapezoidal fuzzy number) to express the approximate intervals, linguistic terms, and unequally possible data set. Zimmermann [9] has introduced a fuzzy linear programming model. It has applied to solve different fuzzy transportation problem (FTP) [10-14]. Chanas et al. [15] proposed a fuzzy linear programming model to determine the solution of an FTP with fuzzy supply and demand, but transportation costs are in real number. Dinagar and Palanivel [16] described an FTP where demand, supply, and transportation costs are trapezoidal fuzzy numbers. Kaur and Kumar [17] have introduced an algorithmic for solving the fuzzy transportation problem. Some researchers used the rough set to handle the uncertainty of transportation problems. Liu [18] has initiated the concept of rough variables to manage the uncertainty of the problem. Xu and Yao [19] have proposed an algorithmic approach for solving the two-person zero-sum matrix games with payoffs as rough variables. Kundu et al. [20] introduced a solid transportation model with crisp and rough costs. Some other researchers [21-30] also have studied this transportation problem in a fuzzy environment.

Usually, human perception $[31,32]$ is used to evaluate the degree of membership of an ordinary fuzzy set, which is a 
crisp value. However, it may not be possible to find an exact membership degree using a type-1 (ordinary) fuzzy set, i.e., fuzzy variable/number because of various types of complications, insufficient information, noises, multiple sources of available data. The type 2 fuzzy set is an extension of a fuzzy set, and it can be used to solve them. Type 2 fuzzy set (T2FS) [33, 34] has also been proposed by Zadeh [33] as an extension of type 1 fuzzy set (T1FS), about 10 years after he has introduced T1FS. Zadeh [33] has described the T2FS as the fuzzy set, which is a mapping from $U$ to $[0,1]$ with the membership function of this set, classified as type 1. The uncertainty associated with the linguistic description of information [35-39] is not represented properly by T1FS due to incorrectness of human perception in the evaluation of membership degrees having crisp values. Mendel and Karnik [40] have enhanced the number of degrees of freedom for fuzzy sets. They have described the idea to add at least one higher degree to T1FSs. It provides a measurement of dispersion for a certain membership degree of T1FS. Hence, T2FS is the extension of the T1FS to a higher degree. T2FSs have a degree of membership that is itself determined by T1FSs. The membership function of T2FS is known as secondary membership functions. T2FS enhances the number of degrees of immunity to handle the ambiguity of the problem T2FS and has a better ability to cover inexact information is logically appropriate behavior. Since the generalized T2FSs are demanding for computation, most of the researchers use interval type-2 fuzzy set (IT2FS) in practical fields [41-48]. Computation in IT2FS is more manageable compared to generalize T2FS. Both IT2F membership function and generalized fuzzy membership function are three dimensions, but the secondary membership value of the IT2F membership function is all-time equal to 1 .

Let $A$ is a type- 1 fuzzy set and $\widetilde{A}$ is an interval type-two fuzzy set as displayed in Figs. 1 and 2, respectively. For a certain value of $x$, say $x_{i}$, a single membership value $r_{1}$ is obtained in $A$. However, there is an interval of membership degree between $r_{1}$ and $r_{2}$ in $\widetilde{A}$ for the same value of $x_{i}$.

The motivation of this paper is to present an algorithmic approach for the transportation problem, which will be simple enough and efficient in real-world situations. In transportation problems, transportation parameters (e.g., demands, supplies, transportation costs) are not always crisp, and that parameters could be uncertain due to several reasons. Therefore, computing the exact parameters in such scenarios could be challenging. Fuzzy can be used in transportation problems to handle this type of uncertainty, and many researchers have described this transportation problem with type 1 fuzzy variables. T2FS extends the degrees of freedom to present uncertainties, and it increases the capacity to deal uncertain/fuzzy/inexact information of any real-life problem in a logically appropriate manner. The main objective of this paper is

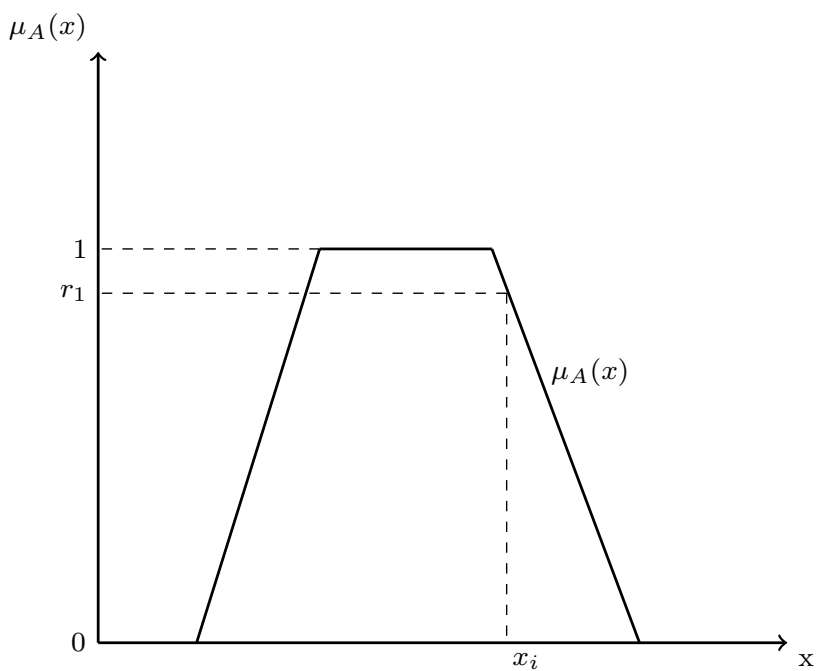

Fig. 1 Crisp grades of membership for type-1 fuzzy set (T1FS) A

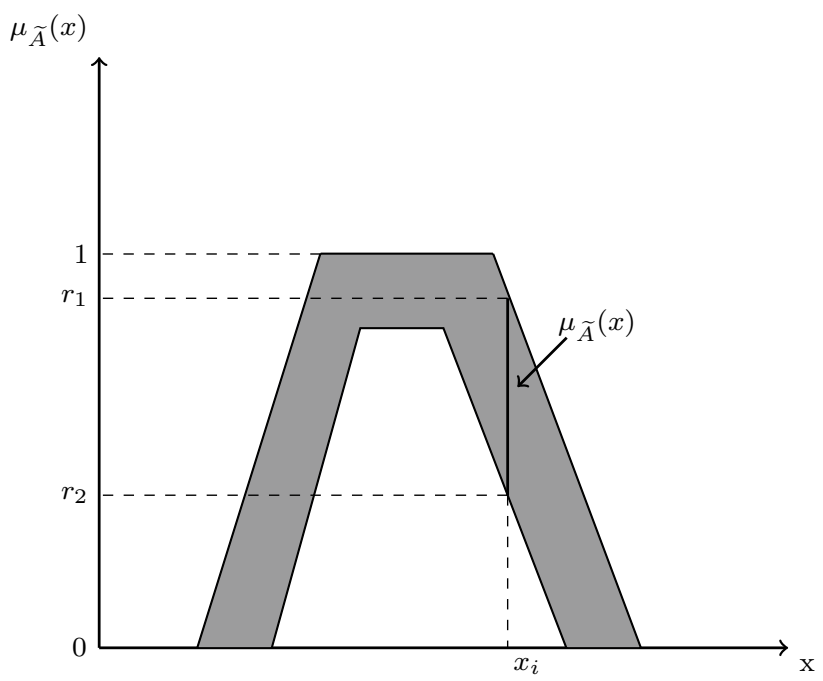

Fig. 2 Fuzzy grades of membership for IT2FS $\widetilde{A}$ (color figure online)

to consider transportation problems with T2FSs. In this paper, we have mainly investigated the following things:

1. We propose an algorithm to solve the fuzzy transportation problem based on Modified Vogel's approximation method (MVAM), where the costs are trapezoidal IT2FSs.

2. We introduce a linear programming problem (LPP) method for solving this problem.

The rest of our paper is arranged as follows.

In Sect. 2, we briefly describe some ideas about the fuzzy set, T1FS, T2FS, IT2FS and centroid-based ranking method [49]. In Sect. 3, we introduce the interval type 2 fuzzy 
transportation problems and some algorithms with flowcharts to solve this problem. In Sect. 4, the two numerical examples are illustrated to describe our proposed algorithm. We present the conclusion in Sect. 5 .

\section{Preliminaries}

Definition 1 Modification form of classical set is called the fuzzy set, where the elements have various degrees of membership. In the classical set, the logic is based on two truth values, either it will be true or it will be false. It is sometimes insufficient when relating human thoughts. Fuzzy logic can use the whole interval between 1 (true) and 0 (false) for better result. A fuzzy set accommodate its members with different membership degrees in the interval $[0,1]$. Let $x$ be an element of $X$, then a fuzzy set $\tilde{A}$ in $X$ is a set of ordered pairs in which the value of $\mu_{\tilde{A}}(x, u)$ lies between 0 and 1 . Here, $x$ is primary variable, $T_{x}$ is primary membership function of $x, u$ is the secondary variable and $\mu_{\widetilde{A}}(x, u)$ is the secondary member function of $x$.

$\tilde{A}=\left\{x, \mu_{\tilde{A}}(x) \mid x \in X\right\}$.

Definition 2 [50]. A T2FS, represented as $\widetilde{A}$, is described by a type- 2 membership function $\mu_{\widetilde{A}}(x, u)$, where $u \in T_{x} \subseteq$ [ $0,1]$ and $x \in X$, i.e.,

$\widetilde{A}=\left\{\left((x, u), \mu_{\widetilde{A}}(x, u)\right) \mid \forall x \in X, \forall u \in T_{x} \subseteq[0,1]\right\}$

$\int_{x \in X} \int_{u \in T_{x}} \mu_{\widetilde{A}}(x, u) /(x, u)$,

where $\iint$ describes union over all primary variable $x$ and secondary variable $u$ and $T_{x} \subseteq[0,1]$. For discrete universes of discourse, $\iint$ is changed by $\sum$.

Definition 3 [50] : IT2FS is a simpler version of T2FS. IT2FS has uniform shading over the footprint of uncertainty (FOU). A T2FS with all $\mu_{\tilde{A}}(x, u)=1$ is named an IT2FS. Let $\widetilde{A}$ represent an IT2FS, then it is described as

$\int_{x \in X} \int_{u \in T_{x}} 1 /(x, u)=\int_{x \in X}\left[\int_{u \in T_{x}} 1 / u\right] / x$,

where primary variable is $x$, the primary membership of $x$ is $T_{x}$ an interval in $[0,1]$, the secondary variable is $u$ and the secondary membership function at $x$ is $\int_{u \in T_{x}} 1 / u$.

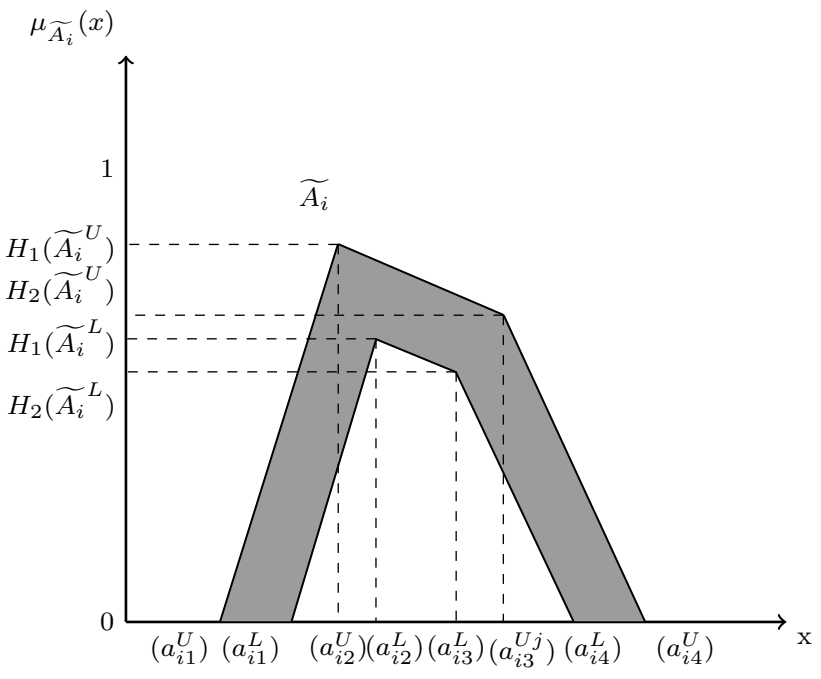

Fig. 3 Trapezoidal interval type 2 fuzzy set (IT2FS) $\widetilde{A_{i}}$ with footprint of uncertainty (FOU) (color figure online)

In this paper, we initiate an algorithmic problem for solving Transportation problem using IT2FS. Heights of the lower and upper membership functions of IT2FS represent an IT2FS of a reference point. We consider trapezoidal IT2FS in our algorithm. A trapezoidal IT2FS $\widetilde{A}$ is shown in Fig. 3. The shaded region is the FOU. It is bounded by a lower membership function (LMF) $\mu_{i}\left(x_{i}\right)$ and an upper membership function (UMF) $\overline{\mu_{i}}\left(x_{i}\right)$. The LMF and UMF have represented type-1 fuzzy sets.

Definition 4 [51]: Let us consider two trapezoidal IT2FSs $\widetilde{A}_{1}$ and $\widetilde{A}_{2}$, where

$$
\begin{aligned}
& \widetilde{A}_{1}=\left(\widetilde{A}_{1}^{U}, \widetilde{A}_{1}^{L}\right)=\left(a_{11}^{U}, a_{12}^{U}, a_{13}^{U}, a_{14}^{U} ; H_{1}\left(\widetilde{A}_{1}^{U}\right), H_{2}\left(\widetilde{A}_{1}^{U}\right)\right) \\
& \left(a_{11}^{L}, a_{12}^{L}, a_{13}^{L}, a_{14}^{L} ; H_{1}\left(\widetilde{A}_{1}^{L}\right), H_{2}\left(\widetilde{A}_{1}^{L}\right)\right) \\
& \widetilde{A}_{2}=\left(\widetilde{A}_{2}^{U}, \widetilde{A}_{2}^{L}\right)=\left(a_{21}^{U}, a_{22}^{U}, a_{23}^{U}, a_{24}^{U} ; H_{1}\left(\widetilde{A}_{2}^{U}\right), H_{2}\left(\widetilde{A}_{2}^{U}\right)\right) \\
& \left(a_{21}^{L}, a_{22}^{L}, a_{23}^{L}, a_{24}^{L} ; H_{1}\left(\widetilde{A}_{2}^{L}\right), H_{2}\left(\widetilde{A}_{2}^{L}\right)\right) .
\end{aligned}
$$

Addition [51] operation $(\oplus)$ among the two trapezoidal IT2FSs $\widetilde{A_{2}}$ and $\widetilde{A_{1}}$ is defined in (5) as follows.

$$
\begin{aligned}
\widetilde{A}_{1}= & \left(\widetilde{A}_{1}^{U}, \widetilde{A}_{1}^{L}\right) \\
= & \left(\left(a_{11}^{U}, a_{12}^{U}, a_{13}^{U}, a_{14}^{U} ; H_{1}\left(\widetilde{A}_{1}^{U}\right), H_{2}\left(\widetilde{A}_{1}^{U}\right)\right)\right. \\
& \left.\left.\left(a_{11}^{L}, a_{12}^{L}, a_{13}^{L}, a_{14}^{L} ; H_{1} \widetilde{A}_{1}^{L}\right), H_{2}\left(\widetilde{A}_{1}^{L}\right)\right)\right)
\end{aligned}
$$

The result of Addition is also a IT2FS. Multiplication [51] operation $(\otimes)$ between the two trapezoidal IT2FSs $\widetilde{A_{1}}$ and $\widetilde{A_{2}}$ is defined in (6) as follows. 


$$
\begin{aligned}
\widetilde{A}_{2}= & \left(\widetilde{A}_{2}^{U}, \widetilde{A}_{2}^{L}\right) \\
= & \left(\left(a_{21}^{U}, a_{22}^{U}, a_{23}^{U}, a_{24}^{U} ; H_{1}\left(\widetilde{A}_{2}^{U}\right), H_{2}\left(\widetilde{A}_{2}^{U}\right)\right)\right. \\
& \left.\left(a_{21}^{L}, a_{22}^{L}, a_{23}^{L}, a_{24}^{L} ; H_{1}\left(\widetilde{A}_{2}^{L}\right), H_{2}\left(\widetilde{A}_{2}^{L}\right)\right)\right)
\end{aligned}
$$

The result of Multiplication is also a IT2FS.

Definition 5 [52]: The centroid value,i.e., $C(\widetilde{B})$ of an IT2FS $\widetilde{B}$ is the union of the centroid values of all its embedded type 1 fuzzy set $B_{e}$ as follows.

$C(\widetilde{B})=\bigcup_{\forall B_{e}} c\left(B_{e}\right)=\left[c_{l}(\widetilde{B}), c_{r}(\widetilde{B})\right]$.

Here $\cup$ represents the union operation and

$c_{l}(\widetilde{B})=\min _{\forall B_{e}}\left(c\left(B_{e}\right)\right)$

$c_{r}(\widetilde{B})=\max _{\forall B_{e}}\left(c\left(B_{e}\right)\right)$

$c\left(B_{e}\right)=\frac{\sum_{i=1}^{N} x_{i} \mu\left(x_{i}\right)}{\sum_{i=1}^{N} \mu\left(x_{i}\right)}$.

It is expressed in [40, 52-54] that $c_{l}(\widetilde{B})$ and $c_{r}(\widetilde{B})$ can be described as follows:

$c_{l}(\widetilde{B})=\frac{\sum_{i=1}^{L} x^{i} \overline{\mu_{i}}\left(x_{i}\right)+\sum_{i=L+1}^{N} x^{i} \underline{\mu_{i}}\left(x_{i}\right)}{\sum_{i=1}^{L} \overline{\mu_{i}}\left(x_{i}\right)+\sum_{i=L+1}^{N} \underline{\mu_{i}}\left(x_{i}\right)}$

$c_{r}(\widetilde{B})=\frac{\sum_{i=1}^{R} x^{i} \underline{\mu_{i}}\left(x_{i}\right)+\sum_{i=R+1}^{N} x^{i} \overline{\mu_{i}}\left(x_{i}\right)}{\sum_{i=1}^{R} \underline{\mu_{i}}\left(x_{i}\right)+\sum_{i=R+1}^{N} \overline{\mu_{i}}\left(x_{i}\right)}$.

Here $R$ and $L$ are right and left switch points. First, we calculate the centroids for IT2FS $\widetilde{B}$, then we find out the average centroid

$C(\widetilde{B})=\frac{c_{l}(\widetilde{B})+c_{r}(\widetilde{B})}{2}$.

Here centroid-based ranking value [49] of IT2FS $\widetilde{B}$ is $C(\widetilde{B})$.

Definition 6 [55]: Let $\widetilde{B}_{1}$ and $\widetilde{B}_{2}$ be considered two interval type 2 fuzzy sets (IT2FSs). Then

The value of IT2FS $\widetilde{B}_{1}$ is greater than $\widetilde{B}_{2}$ if $c\left(\widetilde{B}_{1}\right)>c\left(\widetilde{B}_{2}\right)$.

The value of IT2FS $\widetilde{B}_{1}$ is less than $\widetilde{B}_{2}$ if $c\left(\widetilde{B}_{1}\right)<c\left(\widetilde{B}_{2}\right)$.

The value of IT2FS $\widetilde{B}_{1}$ is equal to $\widetilde{B}_{2}$ if $c\left(\widetilde{B}_{1}\right)=c\left(\widetilde{B}_{2}\right)$.

\section{Proposed algorithm for fuzzy interval type 2 transportation problem}

\section{Mathematical statement}

Suppose that there are $p$ numbers of sources and $q$ destination. Let $\tilde{s}_{i}$ represent the fuzzy numbers of sources $i$ $(i=1,2,3, \ldots, p)$ and let $\tilde{d}_{j}$ represent the fuzzy numbers of destinations $j(j=1,2,3, \ldots, q)$.

Mathematical model of fuzzy transportation problem is given below:

Minimize $\tilde{Z}=\sum_{i=1}^{p} \sum_{j=1}^{q} \tilde{c}_{i j} \tilde{z}_{i j}$,

subject to

$\sum_{j=1}^{q} \tilde{z}_{i j}=\tilde{s}_{i}, \quad i=1,2, \ldots, p$

$\sum_{i=1}^{p} \tilde{z}_{i j}=\tilde{d}_{j}, \quad j=1,2, \ldots, q$

$\tilde{z}_{i j} \geq 0 \quad \forall i, j$,

where $\tilde{c}_{i j}$ is the interval type 2 fuzzy set that represents the transportation cost for one unit from source node $i$ to the destination node $j$ and $\tilde{z}_{i j}$ is the interval type 2 fuzzy set of units transported from source $i$ to destination $j . \tilde{s}_{i}$ is the supply at source $i$ and $\tilde{d}_{j}$ is the demand at destination $j$.

\section{Proposed algorithm 1}

The Vogel's approximation method algorithm is a wellknown algorithm to compute the transportation problem. In this article, we modify the VAM algorithm to handle the transportation problem in a fuzzy environment. Most of the cases, researches use T1FS or fuzzy number as transportation cost value. T1FS is unable to handle the ambiguity due to the inaccuracy of human conception. An interval type-2 fuzzy set (IT2FS) is an extension of the type 1 fuzzy set. IT2FS can handle this ambiguity. The flowchart of modified Vogel's approximation method is shown in Fig. 4.

Step 1: In this problem, the cell cost, demand, and supply are considered as trapezoidal IT2FSs. The centroid value of IT2FS, i.e., the real values of each cell, demand, and supply have computed using Eq. (13). These are used for computation purposes.

Step 2: For the given transportation table, determine the cost of the penalty, distinction between minimum 


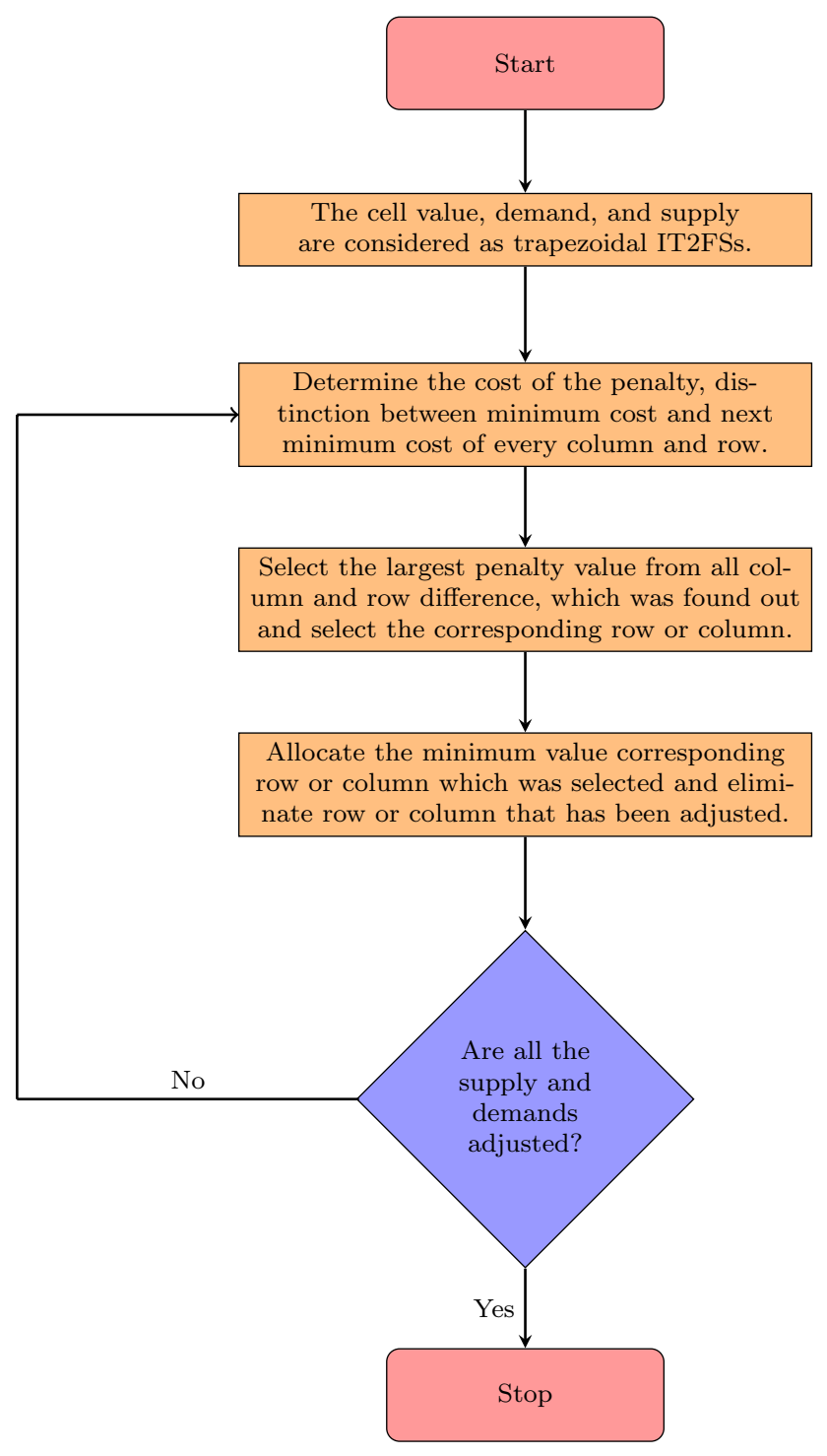

Fig. 4 Flowchart of modified Vogel's approximation method (color figure online)

cost and next minimum cost of every column and rows.

Step 3: Select the largest penalty value from all column and row difference, which is found out in Step 2 and select the corresponding row or column.

Step 4: In this step, select the least cost in row or column which is identified in Step 3.

Step 5: This step allocates minimum value corresponding row and column value which is select in Step 4.

Step 6: Depending upon this cell which column or row has adjusted, this column or row has removed.

Step 7: Same methodology from Step 2 to Step 6 has been applied to the rest of all the unallocated cells until all demands and supplies have been adjusted.

\section{Proposed Algorithm 2}

Step 1: Formulate the given transportation problem into linear programming method using Eqs. (14) and (17).

Step 2 : Using definition of centroid ranking (Definitions 5 and 6), write the standard linear model as given below.

Minimize $\tilde{Z}=\sum_{i=1}^{m} \sum_{j=1}^{n} \tilde{c}_{i j}^{R} \tilde{z}_{i j}$

subject to

$\sum_{j=1}^{n} \tilde{z}_{i j}=\tilde{a}_{i}^{R}, \quad i=1,2, \ldots, m$

$\sum_{i=1}^{m} \tilde{z}_{i j}=\tilde{b}_{j}^{R}, \quad j=1,2, \ldots, n$

$\tilde{z}_{i j} \geq 0 \quad \forall i, j$

where $\tilde{c}_{i j}^{R}=C\left(\tilde{c}_{i j}\right), \tilde{a}_{i}^{R}=C\left(\tilde{a}_{i}\right), \tilde{b}_{j}^{R}=C\left(\tilde{b}_{i}\right), \mathrm{C}$ is the centroid rank.

Step 3: We use Definition 4 in Eq. (19) and find out the crisp standard model.

Step 4: Solve the given problem using the standard linear programming technique and find out the optimal value and objective value.

Step 5: We get the fuzzy optimal cost to use this value in Eq. (14).

Step 6: End.

The flowchart of the proposed LPP method is shown in Fig. 5.

\section{Modified MODI method}

Optimality tests always conduct depend upon the initial basic feasible solution of a transportation problem, where the value of $m+n-1$ is equal to the number of non-negative unoccupied cells and $n$ is the number of columns and $\mathrm{m}$ is the number of row. These all allocated cells stay in an independent position. This type of method always uses for better solutions than the initial basic feasible solution. The flowchart of the modified MODI (MMODI) method is shown in Fig. 6.

Step 1: Calculate $u_{i}$ and $v_{j}$ with the expression $u_{i}+v_{j}=c_{i j}$ for each occupied cell.

Step 2: Consider the value of $u_{i}$ or $v_{j}$ equal to 0 to any row or column, respectively, with having maximum no 


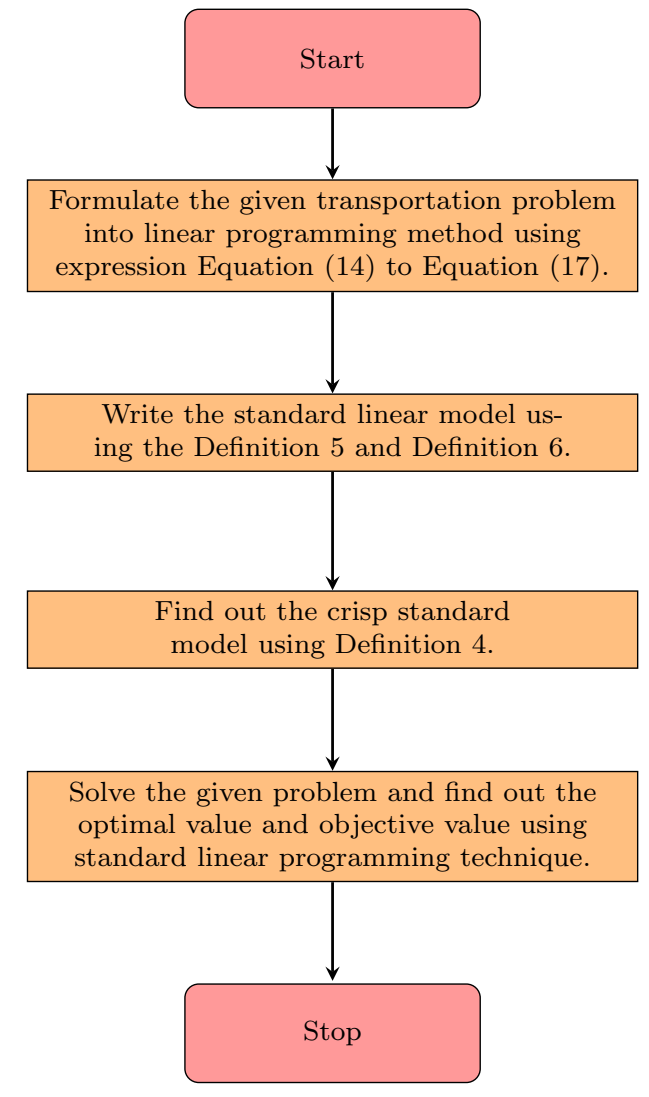

Fig. 5 Flowchart of proposed LPP method

of allocation. If it is more than one then choose any one of them arbitrarily and calculate rest of all $u_{i}$ and $v_{j}$ for all rows and columns, respectively.

Step 3: Compute the value of every unoccupied cell with the equation $\tilde{x}_{i j}=c_{i j}-\left(u_{i}+v_{j}\right)$.

Case I: Have an unique solution and it is an optimal solution if all $\tilde{x}_{i j}>0$.

Case II: Have an alternative solution and it is optimal if all $\tilde{x}_{i j}>=0$.

Case III: It has no optimal solution if $\tilde{x}_{i j}<0$. For that type, the case considers the next step for the optimal solution.

Step 4: If case III occurs, then select the maximum negative value of $\widetilde{x}_{i j}$ and form a close loop with occupied cell and assign "+" and "-" sign alternately. Find out the minimum allocation with a negative sign. It will be added to the positive allocation cell and subtract from the negative allocation cell.

Step 5: Compute and reallocate the occupied cell for finding the new set of basic feasible solutions.

Step 6: Repeat Step 1 to Step 5 until optimal basic feasible solution occurs.

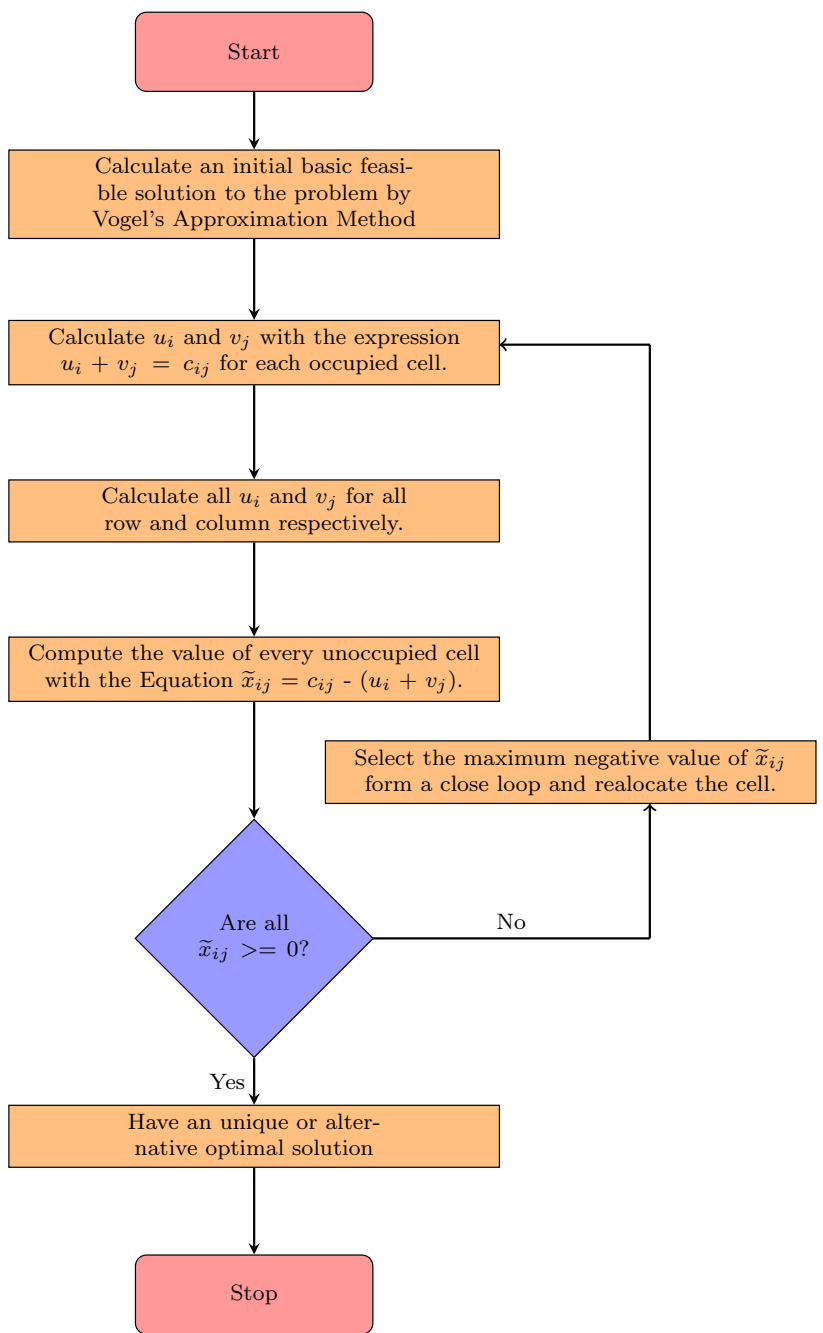

Fig. 6 Flowchart of modified MODI method

\section{Numerical illustration}

We have used two examples for demonstrating our modified Vogel's approximation method to solve FTP with IT2FS cost, i.e., transporting each unit from source to destination.

\section{Numerical Example I}

Now we are consider first example with three supply and four demand base problem and solve it using our proposed modified Vogel's approximation method.

Example 1 We have taken IT2FSs from [56] and which are indexed in Tables 1 and 2. In Table 1, IT2FSs transportation cost is indexed, and in Table 2 IT2FSs supply and demand are indexed. 
Solution: We calculate the centroid based rank of cell cost, demand, and supply using Definitions 5 and 6.

In Table 3, the costs of transportation, supplies, and demands represent as centroid-based ranking values and Table 4 represents the final allocation table of Example I, respectively.

Step 1: Select the first row $\widetilde{S}_{1}$ in Table 3 and calculate the value of the difference between the lowest cost and the next lowest cost, which is 2.87 . Using the same procedure, calculate the value of every corresponding column and row.

Step 2: Select the highest value of these column difference and row difference values say 2.87 .

Step 3: Select minimum cost cell say $\widetilde{C}_{11}$ and allocate the value of the corresponding minimum value of supply and demand say 2.19.

Step 4: Since demand value adjusts with cell allocation value, eliminate the first column say $\widetilde{D}_{1}$

Step 5: For creating a new table, we should be use above steps.

Step 6: The same procedure is used in the rest of the table for finding BFS using the proposed algorithm.

In Table 4, the total number of source $(m)$ is 3 , the total number of destination $(n)$ is 4 , and total number of nonnegative allocation 6 is equal to $m+n-1=3+4-1=6$.

So, it has a basic feasible solution. The total cost can be computed by multiplying the units assigned to the allocated value of each cell with the concerned transportation cost of respective cell.

Therefore, basic feasible solution of the problem $=$ $2.32 * 2.19+7.25 * 3.22+5.19 * 2.19+8.12 * 1.91+$ $2.13 * 3.91+2.13 * 2.59=69.1461$.

\section{Compute optimal value of Example I using MMODI method}

To calculate the optimal value, we use the MMODI method. Tables 5 and 6 represent the initial and final allocation table of MMODI method, respectively. In Table $5, \widetilde{C}_{21}=\widetilde{S}_{2} \widetilde{D}_{1}-\left(\widetilde{S}_{2}+\widetilde{D}_{1}\right)$ is negative and $\widetilde{C}_{31}=\widetilde{S}_{3} \widetilde{D}_{1}-\left(\widetilde{S}_{3}+\widetilde{D}_{1}\right)$ is Negative. Hence, does not have any optimal solution here. Proceed to next step until all $\widetilde{C}_{i j}$ are positive.
In Table 6 , all $\widetilde{C}_{i j}$ are positive. So, there is an optimal solution and this optimal solution is displayed in Table 7. Required optimal solution $=5.19 * 0.28+7.25 * 5.13+2.13 * 2.19+5.19 * 1.91$ $+2.13 * 3.91+2.13 * 2.59=67.0683$, which is more better than the initial basic feasible solution 69.1461 .

Solution of Example 1 using LINGO is 67.0683, which is exactly equal to the optimal solution of proposed algorithm.

Corresponding type 2 fuzzy optimization solution is:

$=0.28 * \widetilde{C}_{12}+5.13 * \widetilde{C}_{13}+2.19 * \widetilde{C}_{21}+1.91 * \widetilde{C}_{22}+$ $3.91 * \widetilde{C}_{24}+2.59 * \widetilde{C}_{34}=((33.6337,56.7825,76.0925$, $104.6313),(57.002,65.8038,65.8038,72.5788,0.27))$.

\section{Numerical Example II}

We considered another example with six supply and eight demand base problems and solve it modified Vogel's approximation algorithm same as the first one.

Example 2 We have taken IT2FSs as transportation cost which are indexed in Tables 8 and 9, assigned to the IT2FSs supply and demand. Table 10 represents the corresponding ranking values and Table 11 represents the required optimal solution of Example II.

Solution: We have calculated the centroid based rank of cost value, demand and supply using Definitions 5 and 6.

Required optimal solution $=378.2358$.

Hence type 2 fuzzy optimization solution is = ((124.3066, 285.530, 440.0125, 674.5364), (351.9588, 3 $53.8824,399.6022,0.27))$.

\section{Results and discussion}

In this study, we have worked on two transportation problems. In the first problem, there are three sources and four destination nodes. We have used IT2FSs to represent those costs. The Lingo software is used to solve this problem. In Example 1, we get IT2FSTP cost is $((33.6337,56.7825,76.0925$, 104.6313), (57.002, 65.8038, 65.8038, 72.5788, 0.27)) and the predicted optimal transportation cost is 67.0683 . Here, it is clear that our predicted cost is within the IT2FS fuzzy. The efficiency of our proposed algorithm is shown in Fig. 7. 
Table 1 The cell costs of the transportation problem represented as IT2FSs for Example I

\begin{tabular}{ll}
\hline Arc & IT2F Cost \\
\hline$\widetilde{C}_{11}$ & $((0.09,1.50,3.00,4.62),(1.79,2.28,2.28,2.81,0.40))$ \\
$\widetilde{C}_{12}$ & $((3.59,4.75,5.50,6.91),(4.86,5.03,5.03,5.14,0.27))$ \\
$\widetilde{C}_{13}$ & $((4.38,6.50,8.25,9.62),(7.19,7.58,7.58,8.21,0.37))$ \\
$\widetilde{C}_{14}$ & $((3.38,5.50,7.50,9.62),(5.79,6.50,6.50,7.21,0.41))$ \\
$\widetilde{C}_{21}$ & $((0.38,1.50,2.50,4.62),(1.09,1.83,1.83,2.21,0.53))$ \\
$\widetilde{C}_{22}$ & $((3.59,4.75,5.50,6.91),(4.86,5.03,5.03,5.14,0.27))$ \\
$\widetilde{C}_{23}$ & $((5.98,7.75,8.60,9.52),(8.03,8.36,8.36,9.17,0.57))$ \\
$\widetilde{C}_{24}$ & $((0.38,1.50,2.50,4.62),(1.09,1.83,1.83,2.21,0.53))$ \\
$\widetilde{C}_{31}$ & $((0.09,1.50,3.00,4.62),(1.79,2.28,2.28,2.81,0.40))$ \\
$\widetilde{C}_{32}$ & $((3.38,5.50,7.50,9.62),(5.79,6.50,6.50,7.21,0.41))$ \\
$\widetilde{C}_{33}$ & $((7.37,9.41,10,10),(8.72,9.91,10,10,1))$ \\
$\widetilde{C}_{34}$ & $((0.38,1.50,2.50,4.62),(1.09,1.83,1.83,2.21,0.53))$ \\
\hline
\end{tabular}

Table 2 The supplies and demands of the transportation problem represented as IT2FSs for Example I

\begin{tabular}{ll}
\hline Arc & IT2F Supply/Demand \\
\hline$\widetilde{S}_{1}$ & $((3.59,4.75,6.00,7.41),(4.79,5.30,5.30,5.71,0.42))$ \\
$\widetilde{S}_{2}$ & $((5.38,7.50,8.75,9.81),(7.79,8.30,8.30,9.21,0.53))$ \\
$\widetilde{S}_{3}$ & $((0.59,2.00,3.25,4.41),(2.29,2.70,2.70,3.21,0.42))$ \\
$\widetilde{D}_{1}$ & $((0.09,1.25,2.50,4.62),(1.67,1.92,1.92,2.21,0.30))$ \\
$\widetilde{D}_{2}$ & $((0.09,1.25,2.50,4.62),(1.67,1.92,1.92,2.21,0.30)))$ \\
$\widetilde{D}_{3}$ & $((2.17,4.25,6.00,7.83),(4.79,5.29,5.29,6.02,0.41))$ \\
$\widetilde{D}_{4}$ & $((3.38,5.50,7.50,9.62),(5.79,6.50,6.50,7.21,0.41))$ \\
\hline
\end{tabular}

Table 3 Initial allocation table of the IT2F transportation problem for Example I

\begin{tabular}{llllll}
\hline & $\widetilde{D}_{1}$ & $\widetilde{D}_{2}$ & $\widetilde{D}_{3}$ & $\widetilde{D}_{4}$ & Supply \\
\hline$\widetilde{S}_{1}$ & 2.32 & 5.19 & 7.25 & 6.50 & 5.41 \\
$\widetilde{S}_{2}$ & 2.13 & 5.19 & 8.12 & 2.13 & 8.01 \\
$\widetilde{S}_{3}$ & 2.32 & 6.50 & 9.30 & 2.13 & 2.59 \\
Demand & 2.19 & 2.19 & 5.13 & 6.50 & 16.01 \\
\hline
\end{tabular}

Table 4 Final allocation table of the IT2F transportation problem for Example I

\begin{tabular}{|c|c|c|c|c|c|c|c|c|c|}
\hline \multirow{2}{*}{$\widetilde{S}_{1}$} & \multicolumn{2}{|c|}{$\widetilde{D}_{1}$} & \multicolumn{2}{|c|}{$\widetilde{D}_{2}$} & \multicolumn{2}{|c|}{$\widetilde{D}_{3}$} & \multicolumn{2}{|c|}{$\widetilde{D}_{4}$} & \multirow{2}{*}{$\begin{array}{c}\text { Supply } \\
5.41\end{array}$} \\
\hline & 2.19 & \multirow[b]{2}{*}{2.32} & \multirow{2}{*}{\multicolumn{2}{|c|}{5.19}} & 3.22 & \multirow[b]{2}{*}{7.25} & \multirow{2}{*}{\multicolumn{2}{|c|}{6.50}} & \\
\hline \multirow{3}{*}{$\widetilde{S}_{2}$} & & & & & & & & & \\
\hline & & & 2.19 & \multirow[b]{2}{*}{5.19} & 1.91 & \multirow[b]{2}{*}{8.12} & 3.91 & \multirow[b]{2}{*}{2.13} & 8.01 \\
\hline & & 2.13 & & & & & & & \\
\hline \multirow[t]{2}{*}{$\widetilde{S}_{3}$} & & & & \multirow[b]{2}{*}{6.50} & & \multirow[b]{2}{*}{9.30} & 2.59 & \multirow[b]{2}{*}{2.13} & 2.59 \\
\hline & & 2.32 & & & & & & & \\
\hline Demand & & & & & & & & & \\
\hline
\end{tabular}

Table 5 Initial allocation table for MMODI method

\begin{tabular}{|c|c|c|c|c|c|c|c|c|c|}
\hline \multirow[b]{2}{*}{$\widetilde{S}_{1}=-0.87$} & \multicolumn{2}{|c|}{$\widetilde{D}_{1}=3.19$} & \multicolumn{2}{|c|}{$\widetilde{D}_{2}=5.19$} & \multicolumn{2}{|c|}{$\widetilde{D}_{3}=8.12$} & \multicolumn{2}{|c|}{$\widetilde{D}_{4}=2.13$} & Supply \\
\hline & 2.19 & \multirow[b]{2}{*}{2.32} & \multirow{2}{*}{\multicolumn{2}{|c|}{5.19}} & 3.22 & \multirow[b]{2}{*}{7.25} & \multirow{2}{*}{\multicolumn{2}{|c|}{6.50}} & 5.41 \\
\hline & & & & & & & & & \\
\hline \multirow[t]{2}{*}{$\widetilde{S}_{2}=0$} & & & 2.19 & \multirow[b]{2}{*}{5.19} & 1.91 & \multirow[b]{2}{*}{8.12} & 3.91 & \multirow[b]{2}{*}{2.13} & 8.01 \\
\hline & & 2.13 & & & & & & & \multirow{3}{*}{2.59} \\
\hline \multirow{2}{*}{$\widetilde{S}_{3}=0$} & & \multirow[b]{2}{*}{2.32} & & \multirow[b]{2}{*}{6.50} & & \multirow[b]{2}{*}{9.30} & 2.59 & \multirow[b]{2}{*}{2.13} & \\
\hline & & & & & & & & & \\
\hline Demand & & & & & & & & & \\
\hline
\end{tabular}

Table 6 Final allocation table of MMODI method

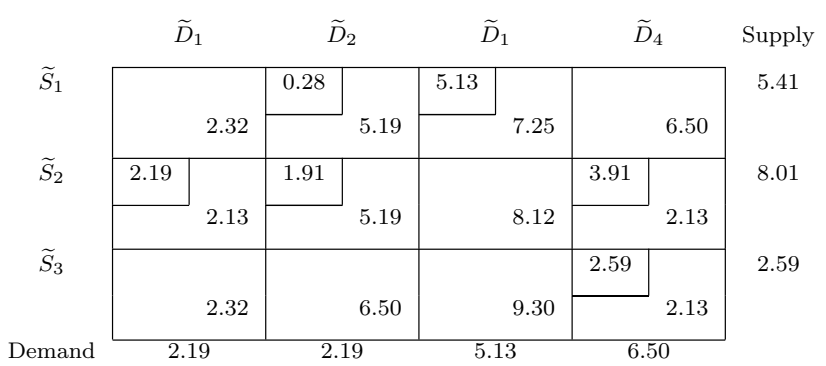

Table 7 Optimal solution of Example I

\begin{tabular}{ll}
\hline Result using LINGO & $\begin{array}{l}\text { Result using our proposed algo- } \\
\text { rithm }\end{array}$ \\
\hline Minimize $\tilde{Z}=67.0683$ & Total cost $=67.0683$ \\
$\tilde{x}_{12}=0.28, \tilde{x}_{13}=5.13, \tilde{x}_{21}=2.19$ & Optimal transportation value are \\
$\tilde{x}_{22}=1.91, \tilde{x}_{24}=3.91, \tilde{x}_{34}=2.59$ & $\tilde{x}_{12}=0.28, \tilde{x}_{13}=5.13, \widetilde{x}_{21}=2.19$ \\
& $\tilde{x}_{22}=1.91, \tilde{x}_{24}=3.91, \tilde{x}_{34}=2.59$ \\
\hline
\end{tabular}


Table 8 The cell costs of the transportation problem represented as IT2FSs for Example II

\begin{tabular}{|c|c|}
\hline Arc & IT2F Cost \\
\hline$\widetilde{C}_{11}$ & $((0.38,1.50,2.50,4.62),(1.09,1.83,1.83,2.21,0.53))$ \\
\hline$\widetilde{C}_{12}$ & $((5.38,7.50,8.75,9.81),(7.79,8.22,8.22,8.81,0.45))$ \\
\hline$\widetilde{C}_{13}$ & $((5.38,7.50,9.00,9.81),(8.29,7.56,8.56,9.21,0.38)$ \\
\hline$\widetilde{C}_{14}$ & $((2.59,4.00,5.50,7.62),(4.29,4.75,4.75,5.21,0.38))$ \\
\hline$\widetilde{C}_{15}$ & $((3.59,4.75,5.50,6.91),(7.86,5.03,5.03,5.14,0.27))$ \\
\hline$\widetilde{C}_{16}$ & $((3.38,5.50,7.50,9.62),(5.79,6.50,6.50,7.21,0.41))$ \\
\hline$\widetilde{C}_{17}$ & $((4.38,6.50,8.00,9.41),(6.79,7.38,7.38,8.21,0.49))$ \\
\hline$\widetilde{C}_{18}$ & $((5.38,7.50,8.75,9.83),(7.69,8.19,8.19,8.81,0.47))$ \\
\hline$\widetilde{C}_{21}$ & $((4.38,6.50,8.00,9.41),(6.79,7.38,7.38,8.21,0.49))$ \\
\hline$\widetilde{C}_{22}$ & $((0.09,1.50,3.00,4.62),(1.79,2.28,2.28,2.81,0.40))$ \\
\hline$\widetilde{C}_{23}$ & $((0.38,2.50,5.00,7.83),(2.88,3.61,3.61,4.21,0.35))$ \\
\hline$\widetilde{C}_{24}$ & $((5.38,7.50,8.75,9.81),(7.79,8.30,8.30,9.21,0.53)$ \\
\hline$\widetilde{C}_{25}$ & $((3.59,4.75,5.50,6.91),(7.86,5.03,5.03,5.14,0.27))$ \\
\hline$\widetilde{C}_{26}$ & $((3.59,4.75,6.00,7.41),(4.79,5.30,5.30,5.71,0.42))$ \\
\hline$\widetilde{C}_{27}$ & $((0.38,1.50,2.50,4.62),(1.09,1.83,1.83,2.21,0.53))$ \\
\hline$\widetilde{C}_{28}$ & $((3.59,4.75,6.00,7.41),(4.79,5.30,5.30,5.71,0.42))$ \\
\hline$\widetilde{C}_{31}$ & $((0.09,1.50,3.00,4.62),(1.79,2.28,2.28,2.81,0.40))$ \\
\hline$\widetilde{C}_{32}$ & $((3.38,5.50,7.50,9.62),(5.79,6.50,6.50,7.21,0.41))$ \\
\hline$\widetilde{C}_{33}$ & $((5.38,7.50,8.75,9.81),(7.79,8.22,8.22,8.81,0.45))$ \\
\hline$\widetilde{C}_{34}$ & $((0.38,2.50,5.00,7.83),(2.88,3.61,3.61,4.21,0.35))$ \\
\hline$\widetilde{C}_{35}$ & $((2.17,4.25,6.00,7.83),(4.79,5.29,5.29,6.02,0.41))$ \\
\hline$\widetilde{C}_{36}$ & $((5.98,7.75,8.60,9.52),(8.03,8.36,8.36,9.17,0.57))$ \\
\hline$\widetilde{C}_{37}$ & $((2.17,4.25,6.00,7.83),(4.79,5.29,5.29,6.02,0.41))$ \\
\hline$\widetilde{C}_{38}$ & $((4.38,6.50,8.00,9.41),(6.79,7.38,7.38,8.21,0.49))$ \\
\hline$\widetilde{C}_{41}$ & $((0.38,2.50,5.00,7.83),(2.88,3.61,3.61,4.21,0.35))$ \\
\hline$\widetilde{C}_{42}$ & $((4.38,6.50,8.00,9.41),(6.79,7.38,7.38,8.21,0.49))$ \\
\hline$\widetilde{C}_{43}$ & $((1.17,3.50,5.50,7.83),(4.09,4.65,4.65,5.41,0.40))$ \\
\hline$\widetilde{C}_{44}$ & $((1.17,3.50,5.50,7.83),(4.09,4.65,4.65,5.41,0.40))$ \\
\hline$\widetilde{C}_{45}$ & $((2.59,4.00,5.50,7.62),(4.29,4.75,4.75,5.21,0.38))$ \\
\hline$\widetilde{C}_{46}$ & $((5.38,7.50,9.00,9.81),(8.29,7.56,8.56,9.21,0.38)$ \\
\hline$\widetilde{C}_{47}$ & $((3.59,4.75,6.00,7.41),(4.79,5.30,5.30,5.71,0.42))$ \\
\hline
\end{tabular}

Table 8 (continued)

\begin{tabular}{ll}
\hline Arc & IT2F Cost \\
$\widetilde{C}_{48}$ & $((0.09,1.25,2.50,4.62),(1.67,1.92,1.92,2.21,0.30))$ \\
$\widetilde{C}_{51}$ & $((3.59,4.75,6.00,7.41),(4.79,5.30,5.30,5.71,0.42))$ \\
$\widetilde{C}_{52}$ & $((0.59,2.00,3.25,4.41),(2.29,2.70,2.70,3.21,0.42))$ \\
$\widetilde{C}_{53}$ & $((5.38,7.50,8.75,9.81),(7.79,8.22,8.22,8.81,0.45))$ \\
$\widetilde{C}_{54}$ & $((4.38,6.50,8.00,9.41),(6.79,7.38,7.38,8.21,0.49))$ \\
$\widetilde{C}_{55}$ & $((3.38,5.50,7.50,9.62),(5.79,6.50,6.50,7.21,0.41))$ \\
$\widetilde{C}_{56}$ & $((3.59,4.75,5.50,6.91),(7.86,5.03,5.03,5.14,0.27))$ \\
$\widetilde{C}_{57}$ & $((4.38,6.50,8.00,9.41),(6.79,7.38,7.38,8.21,0.49))$ \\
$\widetilde{C}_{58}$ & $((0.09,1.50,3.00,4.62),(1.79,2.28,2.28,2.81,0.40))$ \\
$\widetilde{C}_{61}$ & $((0.09,1.25,2.50,4.62),(1.67,1.92,1.92,2.21,0.30))$ \\
$\widetilde{C}_{62}$ & $((0.09,1.50,3.00,4.62),(1.79,2.28,2.28,2.81,0.40))$ \\
$\widetilde{C}_{63}$ & $((0.09,1.25,2.50,4.62),(1.67,1.92,1.92,2.21,0.30))$ \\
$\widetilde{C}_{64}$ & $((3.59,4.75,6.00,7.41),(4.79,5.30,5.30,5.71,0.42))$ \\
$\widetilde{C}_{65}$ & $((4.38,6.50,8.00,9.41),(6.79,7.38,7.38,8.21,0.49))$ \\
$\widetilde{C}_{66}$ & $((4.38,6.50,8.25,9.62),(7.19,7.58,7.58,8.21,0.37))$ \\
$\widetilde{C}_{67}$ & $((3.38,5.50,7.50,9.62),(5.79,6.50,6.50,7.21,0.41))$ \\
$\widetilde{C}_{68}$ & $((4.38,6.50,8.25,9.62),(7.19,7.58,7.58,8.21,0.37))$ \\
\hline
\end{tabular}

Table 9 The supplies and demands of the transportation problem represented as IT2FSs for Example II

\begin{tabular}{|c|c|}
\hline Arc & IT2F Supply/Demand \\
\hline$\widetilde{S}_{1}$ & $((18.68,19.91,20.00,20.00),(19.61,19.97,20.00,20.00,1.00))$ \\
\hline$\widetilde{S}_{2}$ & $\begin{array}{l}\left(\left(\begin{array}{l}17.37,19.73,20.00,20.00),(19.34,19.95,20.00,20.00) \\
1.00))\end{array}\right.\right.\end{array}$ \\
\hline$\widetilde{S}_{3}$ & $\begin{array}{l}((17.37,19.82,20.00,20.00),(19.37,19.95,20.00,20.00) \\
\quad 1.00))\end{array}$ \\
\hline$\widetilde{S}_{4}$ & $\begin{array}{l}\left(\left(\begin{array}{c}17.37,19.82,20.00,20.00),(19.74,19.98,20.00,20.00 \\
1.00))\end{array}\right.\right.\end{array}$ \\
\hline$\widetilde{S}_{5}$ & $\begin{array}{l}\left(\left(\begin{array}{c}17.37,19.59,20.00,20.00),(18.95,19.93,20.00,20.00 \\
1.00))\end{array}\right.\right.\end{array}$ \\
\hline$\widetilde{S}_{6}$ & $\begin{array}{l}\left(\left(\begin{array}{l}17.37,19.41,20.00,20.00),(18.72,19.91,20.00,20.00 \\
1.00))\end{array}\right.\right.\end{array}$ \\
\hline$\widetilde{D}_{1}$ & $\begin{array}{l}\left(\left(\begin{array}{l}15.38,17.50,18.75,19.81),(17.79,18.22,18.22,18.81 \\
0.45))\end{array}\right.\right.\end{array}$ \\
\hline$\widetilde{D}_{2}$ & $\begin{array}{l}\left(\left(\begin{array}{l}14.38,16.50,18.25,19.62),(17.19,17.58,17.58 \\
18.21,0.37))\end{array}\right.\right.\end{array}$ \\
\hline$\widetilde{D}_{3}$ & $((5.38,7.50,8.75,9.81),(7.79,8.22,8.22,8.81,0.45))$ \\
\hline$\widetilde{D}_{4}$ & $\begin{array}{l}\left(\left(\begin{array}{c}13.38,15.50,17.50,19.62),(15.79,16.50,16.50, \\
17.21,0.41))\end{array}\right.\right.\end{array}$ \\
\hline$\widetilde{D}_{5}$ & $\begin{array}{l}\left(\left(\begin{array}{l}13.59,14.75,15.50,16.91),(17.86,15.03,15.03 \\
15.14,0.27))\end{array}\right.\right.\end{array}$ \\
\hline$\widetilde{D}_{6}$ & $\begin{array}{l}\left(\left(\begin{array}{l}14.38,16.50,18.00,19.41),(16.79,17.38,17.38 \\
18.21,0.49))\end{array}\right.\right.\end{array}$ \\
\hline$\widetilde{D}_{7}$ & $\begin{array}{l}\left(\left(\begin{array}{c}13.59,14.75,15.50,16.91),(17.86,15.03,15.03, \\
15.14,0.27))\end{array}\right.\right.\end{array}$ \\
\hline$\widetilde{D}_{8}$ & $((7.37,9.41,10.00,10.00),(8.72,9.91,10.00,10.00,1.00))$ \\
\hline
\end{tabular}


Table 10 The cell cost, supply and demand of the IT2F transportation problem for Example II, represented as centroid base ranking value

\begin{tabular}{llllllllll}
\hline Source & $\widetilde{D}_{1}$ & $\widetilde{D}_{2}$ & $\widetilde{D}_{3}$ & $\widetilde{D}_{4}$ & $\widetilde{D}_{5}$ & $\widetilde{D}_{6}$ & $\widetilde{D}_{7}$ & $\widetilde{D}_{8}$ & Supply \\
\hline$\widetilde{S}_{1}$ & 2.13 & 7.90 & 8.03 & 4.95 & 5.19 & 6.50 & 7.16 & 7.91 & 19.69 \\
$\widetilde{S}_{2}$ & 7.16 & 2.32 & 3.90 & 8.01 & 5.19 & 5.41 & 2.13 & 5.41 & 19.37 \\
$\widetilde{S}_{3}$ & 2.32 & 6.50 & 7.90 & 3.90 & 5.13 & 8.12 & 5.13 & 7.16 & 19.38 \\
$\widetilde{S}_{4}$ & 3.90 & 7.16 & 4.56 & 4.56 & 4.95 & 8.03 & 5.41 & 2.19 & 19.31 \\
$\widetilde{S}_{5}$ & 5.41 & 2.59 & 7.90 & 7.16 & 6.50 & 5.19 & 7.16 & 2.32 & 19.34 \\
$\widetilde{S}_{6}$ & 2.19 & 2.32 & 2.19 & 5.41 & 7.16 & 7.25 & 6.50 & 7.25 & 19.30 \\
Demand & 17.90 & 17.25 & 7.90 & 16.50 & 15.19 & 17.16 & 15.19 & 9.30 & 116.39 \\
\hline
\end{tabular}

Table 11 Optimal solution of Example II

\begin{tabular}{ll}
\hline Result using LINGO & Result using proposed algorithm \\
\hline Minimize $\tilde{Z}=378.2358$ & Total cost $=378.2358$ \\
$\tilde{x}_{11}=17.90, \widetilde{x}_{15}=1.79$, & Optimal value $=$ \\
$\widetilde{x}_{22}=4.18$ & \\
$\widetilde{x}_{27}=15.19, \widetilde{x}_{34}=16.50$, & $\widetilde{x}_{11}=17.90, \widetilde{x}_{15}=1.79$, \\
$\widetilde{x}_{35}=2.88$ & $\widetilde{x}_{22}=4.18$ \\
$\widetilde{x}_{45}=10.52, \widetilde{x}_{48}=8.79$, & $\widetilde{x}_{27}=15.19, \widetilde{x}_{34}=16.50$, \\
$\widetilde{x}_{52}=1.67$ & $\widetilde{x}_{35}=2.88$ \\
$\widetilde{x}_{56}=17.16, \widetilde{x}_{58}=0.51$, & $\widetilde{x}_{45}=10.52, \widetilde{x}_{48}=8.79$, \\
$\widetilde{x}_{62}=11.4$ & $\widetilde{x}_{52}=1.67$ \\
$\widetilde{x}_{63}=7.90$ & $\widetilde{x}_{56}=17.16, \widetilde{x}_{58}=0.51$ \\
& $\widetilde{x}_{62}=11.4, \widetilde{x}_{63}=7.90$ \\
\hline
\end{tabular}

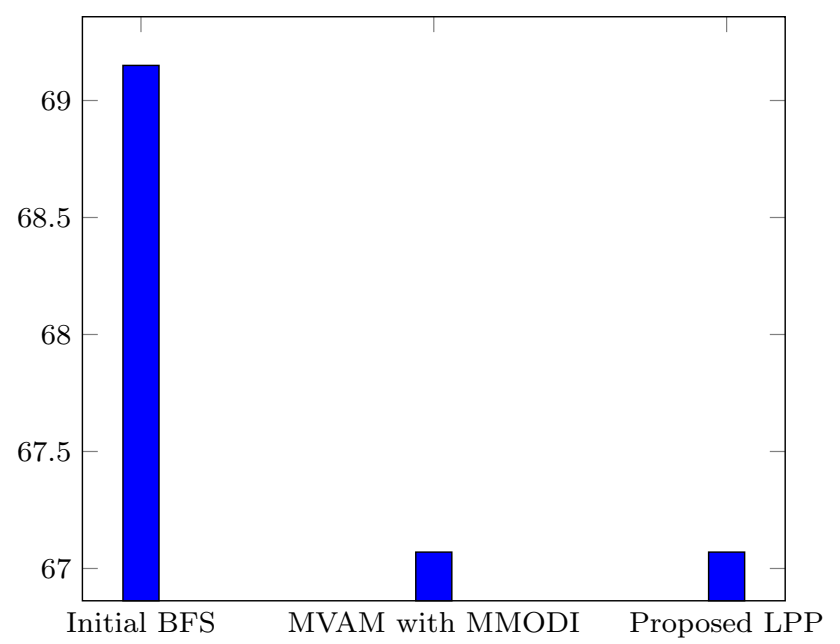

Fig. 7 Comparison chart of our proposed algorithms for Numerical Example I

\section{Conclusion}

The VAM algorithm is a common algorithm to solve the transportation problem. In this paper, the classical VAM algorithm is modified to solve the fuzzy transportation problem fuzzy. We represent all the demand, supply, and transportation costs as IT2FSs. The idea of our proposed algorithm is elementary and effective to apply for realworld scenarios, e.g., management, transportation system, and many other network optimization problems. Here, we present two small numerical examples to demonstrate our proposed algorithm. Therefore, as future research, we have to solve a large scale practical transportation problem using the proposed algorithm. Furthermore, we will try to modify our proposed algorithm for the Pythagorean fuzzy set [57] and interval type-2 intuitionistic fuzzy sets [58-61].

Open Access This article is licensed under a Creative Commons Attribution 4.0 International License, which permits use, sharing, adaptation, distribution and reproduction in any medium or format, as long as you give appropriate credit to the original author(s) and the source, provide a link to the Creative Commons licence, and indicate if changes were made. The images or other third party material in this article are included in the article's Creative Commons licence, unless indicated otherwise in a credit line to the material. If material is not included in the article's Creative Commons licence and your intended use is not permitted by statutory regulation or exceeds the permitted use, you will need to obtain permission directly from the copyright holder. To view a copy of this licence, visit http://creativecommons.org/licenses/by/4.0/.

\section{References}

1. Peng X, Dai J, Garg H (2018) Exponential operation and aggregation operator for q-rung orthopair fuzzy set and their decision-making method with a new score function. Int J Intell Syst 33(11):2255-2282

2. Kumar R, Edalatpanah SA, Jha S, Broumi S, Singh R, Dey A (2019) A multi objective programming approach to solve integer valued neutrosophic shortest path problems. Neutrosophic Sets Syst 24:134-149

3. Zhao H, Xu L, Guo Z, Liu W, Zhang Q, Ning X, Li G, Shi L (2019) A new and fast waterflooding optimization workflow based on insim-derived injection efficiency with a field application. $\mathbf{J}$ Petrol Sci Eng 179:1186-1200

4. Garg H (2016) A new generalized pythagorean fuzzy information aggregation using einstein operations and its application to decision making. Int J Intell Syst 31(9):886-920

5. Kumar R, Edalatpanah SA, Jha S, Singh R (2019) A novel approach to solve gaussian valued neutrosophic shortest path problems. Int J Eng Adv Technol 8(3):347-353 
6. Kumar R, Jha S, Singh R (2020) A different approach for solving the shortest path problem under mixed fuzzy environment. Int $\mathrm{J}$ Fuzzy Syst Appl 9(2):132-161

7. Kumar R, Edalatpanah SA, Jha S, Gayen S, Singh R (2019) Shortest path problems using fuzzy weighted arc length. Int J Innovat Technol Explor Eng 8(6):724-731

8. Sheng G, Su Y, Wang W (2019) A new fractal approach for describing induced-fracture porosity/permeability/compressibility in stimulated unconventional reservoirs. J Petrol Sci Eng 179:855-66

9. Zimmermann HJ (1978) Fuzzy programming and linear programming with several objective functions. Fuzzy Sets Syst 1(1):45-55

10. Maity G, Mardanya D, Roy SK, Weber GW (2019) A new approach for solving dual-hesitant fuzzy transportation problem with restrictions. Sādhana 44(4):75

11. Majumder S, Kundu P, Kar S, Pal T (2019) Uncertain multiobjective multi-item fixed charge solid transportation problem with budget constraint. Soft Comput 23(10):3279-3301

12. Roy SK, Midya S (2019) Multi-objective fixed-charge solid transportation problem with product blending under intuitionistic fuzzy environment. Appl Intell 49(10):3524-3538

13. Maity G, Roy SK, Verdegay JL (2019) Time variant multi-objective interval-valued transportation problem in sustainable development. Sustainability 11(21):6161

14. Roy SK, Midya S, Vincent FY (2018) Multi-objective fixedcharge transportation problem with random rough variables. Int $\mathrm{J}$ Uncertain Fuzzy Knowl Based Syst 26(6):971-996

15. Chanas S, Kołodziejczyk W, Machaj A (1984) A fuzzy approach to the transportation problem. Fuzzy Sets Syst 13(3):211-221

16. Dinagar DS, Palanivel K (2009) The transportation problem in fuzzy environment. Int J Algorithm Comput Math 2(3):65-71

17. Kaur A, Kumar A (2012) A new approach for solving fuzzy transportation problems using generalized trapezoidal fuzzy numbers. Appl Soft Comput 12(3):1201-1213

18. Liu B (2004) Uncertainty theory: an introduction to its axiomatic foundations. Springer, Berlin

19. Xu J, Yao L (2010) A class of two-person zero-sum matrix games with rough payoffs. Int J Math Math Sci 2010:404792

20. Kundu P, Kar S, Maiti M (2013) Some solid transportation models with crisp and rough costs. In Proceedings of World Academy of Science, Engineering and Technology, number 73, page 185. World Academy of Science, Engineering and Technology (WASET)

21. Jiménez F, Verdegay J (1999) Solving fuzzy solid transportation problems by an evolutionary algorithm based parametric approach. Eur J Oper Res 117(3):485-510

22. Kundu P, Kar S, Maiti M (2013) Multi-objective multi-item solid transportation problem in fuzzy environment. Appl Math Model 37(4):2028-2038

23. Garg H, Nancy (2016) An improved score function for ranking neutrosophic sets and its application to decision-making process. Int J Uncertain Quant 6(5):377-385

24. Kundu P, Kar S, Maiti M (2014) Multi-objective solid transportation problems with budget constraint in uncertain environment. Int J Syst Sci 45(8):1668-1682

25. Garg H (2018) Non-linear programming method for multi-criteria decision making problems under interval neutrosophic set environment. Appl Intell 48(8):2199-2213

26. Ojha A, Das B, Mondal S, Maiti M (2009) An entropy based solid transportation problem for general fuzzy costs and time with fuzzy equality. Math Comput Modell 50(1-2):166-178

27. Yang L, Liu L (2007) Fuzzy fixed charge solid transportation problem and algorithm. Appl Soft Comput 7(3):879-889

28. Garg HN (2018) Multi-criteria decision-making method based on prioritized muirhead mean aggregation operator under neutrosophic set environment. Symmetry 10(7):280
29. Garg HN (2017) Some new biparametric distance measures on single-valued neutrosophic sets with applications to pattern recognition and medical diagnosis. Information 8(4):162

30. Garg H (2017) A novel improved accuracy function for interval valued pythagorean fuzzy sets and its applications in the decisionmaking process. Int J Intell Syst 32(12):1247-1260

31. Garg HN (2018) Some hybrid weighted aggregation operators under neutrosophic set environment and their applications to multicriteria decision-making. Appl Intell 48(12):4871-4888

32. Garg HN (2018) New logarithmic operational laws and their applications to multiattribute decision making for single-valued neutrosophic numbers. Cognit Syst Res 52:931-946

33. Zadeh LA (1975) The concept of a linguistic variable and its application to approximate reasoning. Inf Sci 8(3):199-249

34. Mendel JM, John RIB (2002) Type-2 fuzzy sets made simple. Fuzzy Syst IEEE Trans 10(2):117-127

35. Garg H (2017) Generalized pythagorean fuzzy geometric aggregation operators using einstein t-norm and t-conorm for multicriteria decision-making process. Int J Intell Syst 32(6):597-630

36. Garg H (2016) A novel accuracy function under interval-valued pythagorean fuzzy environment for solving multicriteria decision making problem. J Intell Fuzzy Syst 31(1):529-540

37. Garg H, Rani M, Sharma SP, Vishwakarma Y (2014) Intuitionistic fuzzy optimization technique for solving multi-objective reliability optimization problems in interval environment. Expert Syst Appl 41(7):3157-3167

38. Garg H, Singh S (2020) Algorithm for solving group decisionmaking problems based on the similarity measures under type 2 intuitionistic fuzzy sets environment. Soft Comput 24:7361-7381

39. Garg H, Singh S (2018) A novel triangular interval type-2 intuitionistic fuzzy sets and their aggregation operators. Iran J Fuzzy Syst 15:19-93

40. Mendel JM, Liu F (2007) Super-exponential convergence of the karnik-mendel algorithms for computing the centroid of an interval type-2 fuzzy set. Fuzzy Syst IEEE Trans 15(2):309-320

41. Dereli T, Altun K (2013) Technology evaluation through the use of interval type-2 fuzzy sets and systems. Comput Ind Eng 65(4):624-633

42. Kar MB, Kundu P, Kar S, Pal T (2018) A multi-objective multiitem solid transportation problem with vehicle cost, volume and weight capacity under fuzzy environment. J Intell Fuzzy Syst 35(2):1991-1999

43. Chen SM, Yang MW, Yang SW, Sheu TW, Liau CJ (2012) Multicriteria fuzzy decision making based on interval-valued intuitionistic fuzzy sets. Exp Syst Appl 39(15):12085-12091

44. Wang W, Liu X, Qin Y (2012) Multi-attribute group decision making models under interval type-2 fuzzy environment. Knowl Based Syst 30:121-128

45. Chen TY (2013) A linear assignment method for multiple-criteria decision analysis with interval type- 2 fuzzy sets. Appl Soft Comput 13(5):2735-2748

46. Kundu P, Majumder S, Kar S, Maiti M (2019) A method to solve linear programming problem with interval type-2 fuzzy parameters. Fuzzy Optim Decis Making 18(1):103-130

47. De A, Kundu P, Das S, Kar S (2020) A ranking method based on interval type-2 fuzzy sets for multiple attribute group decision making. Soft Comput 24(1):131-154

48. Kundu P, Kar S, Maiti M (2015) Multi-item solid transportation problem with type-2 fuzzy parameters. Appl Soft Comput 31:61-80

49. Wu D, Mendel JM (2009) A comparative study of ranking methods, similarity measures and uncertainty measures for interval type-2 fuzzy sets. Inf Sci 179(8):1169-1192

50. Mendel JM, John RI, Liu F (2006) Interval type-2 fuzzy logic systems made simple. Fuzzy Syst IEEE Trans 14(6):808-821

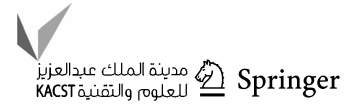


51. Lee LW, Chen SM (2008) A new method for fuzzy multiple attributes group decision-making based on the arithmetic operations of interval type-2 fuzzy sets. In: Machine learning and cybernetics, 2008 international conference on, vol 6, pp 3084-3089. IEEE

52. Karnik NN, Mendel JM (2001) Centroid of a type-2 fuzzy set. Inf Sci 132(1):195-220

53. Mendel JM (2001) Uncertain rule-based fuzzy systems: introduction and new directions. Springer, Cham, pp 213-231

54. Yager RR (1978) Ranking fuzzy subsets over the unit interval. In: Decision and control including the 17th symposium on adaptive processes, 1978 IEEE conference on, vol 17, pp 1435-1437

55. Dey A, Pal A, Long HV, Son LH (2020) Fuzzy minimum spanning tree with interval type 2 fuzzy arc length: formulation and a new genetic algorithm. Soft Comput 24(6):3963-3974

56. Mendel JM (2007) Computing with words: Zadeh, turing, popper and occam. IEEE Comput Intell Magn 2(4):10-17

57. Peng X, Selvachandran G (2019) Pythagorean fuzzy set: state of the art and future directions. Artif Intell Rev 52(3):1873-1927
58. Singh S, Garg H (2018) Symmetric triangular interval type-2 intuitionistic fuzzy sets with their applications in multi criteria decision making. Symmetry 10(9):401

59. Singh S, Garg H (2017) Distance measures between type-2 intuitionistic fuzzy sets and their application to multicriteria decisionmaking process. Appl Intell 46(4):788-799

60. Roy SK, Maity G, Weber GW (2017) Conic scalarization approach to solve multi-choice multi-objective transportation problem with interval goal. Ann Oper Res 253(1):599-620

61. Roy SK, Ebrahimnejad A, Verdegay JL, Das S (2018) New approach for solving intuitionistic fuzzy multi-objective transportation problem. Sādhanā 43(1):3

Publisher's Note Springer Nature remains neutral with regard to jurisdictional claims in published maps and institutional affiliations. 